\title{
Effect of photoperiod, injection of pentobarbitone sodium or lesion of the suprachiasmatic nucleus on pre-partum decrease of blood progesterone concentrations or time of birth in the rat
}

\author{
N. Murakami, T. Abe, M. Yokoyama, A. Katsume*, H. Kuroda and \\ T. Etoh \\ Department of Veterinary Physiology, Pathology*, Faculty of Agriculture, University of Miyazaki, \\ Miyazaki 889-21, Japan
}

\begin{abstract}
Summary. In Sprague-Dawley rats kept under 14L:10D (lights on 05:00-19:00 h), parturition occurred during the light phase on Day 23, and the pre-partum decrease in progesterone concentrations was observed between 07:00 and 15:00 h during the light period on Day 22. When the rats were transferred to reversed light-dark regimen (lights on 17:00-07:00 h) on Day 7, the progesterone decrease and parturition still occurred during the light period on Day 21 and 22-23, respectively. However, when rats were kept in constant darkness from Day 7 , parturition occurred independently of the time of day between Day 22 and 24. A gradual decline of progesterone concentrations was randomly observed in individual rats. In Wistar rats kept under the usual light-dark regimen, parturitions were biphasic, occurring during the light periods on Day 22 and 23. The progesterone decrease occurred at the usual time even when the lighting regimen was changed only on the day of the expected progesterone decrease. However, treatment with pentobarbitone sodium at 15:00, 19:00 or 21:00 h, but not at 12:00 or 23:00 h, on Day 21 resulted in a delay of progesterone decrease and of parturition. Complete lesion of the suprachiasmatic nucleus on Day 13 or 14 led to advancement and random distribution of the time of birth.

These results suggest that the time of parturition and of pre-partum progesterone decrease may be closely associated with an endogenous circadian system, and a luteolytic factor involving the nervous system may be present during a limited period before parturition.
\end{abstract}

\section{Introduction}

Parturition in rats generally occurs during the light period in a light-dark regimen (Mitchell \& Yochim, 1970; Plaut et al., 1970; Lincoln \& Porter, 1976, 1979; Bosc \& Nicolle, 1980; Sherwood et al., 1983). This specific effect of the light on the time of parturition has been suggested in experiments involving shifts of photoperiod near mid-pregnancy (Lincoln \& Porter, 1976; Sherwood et al., 1983) or different light regimens, such as reversed light-dark cycles or extension of the light period each day (Mitchell \& Yochim, 1970; Plaut et al., 1970; Bosc \& Nicolle, 1980). A link between the daily photoperiod and the time of birth may therefore be associated with an endogenous circadian rhythm of the rat (Lincoln \& Doyle, 1978; Lincoln \& Porter, 1979). A pre-partum increase of serum relaxin and decline of progesterone concentrations have also been suggested as being associated with the photoperiod. Sherwood et al. (1983) showed that the time of birth, maximal relaxin concentrations and decline of progesterone values during the pre-partum period were 
advanced by alteration of the photoperiod near mid-pregnancy. As far as we know, however, there has been little study of the pre-partum decrease of blood progesterone concentrations under various lighting conditions (Bartholomeusz et al., 1976; Sanyal, 1978). In our colony of Sprague Dawley rats, parturition occurs at 09:00-15:00 h on Day 23. However, these hours of birth seem to be different from those reported for Wistar (Lincoln \& Porter, 1976; Bosc \& Nicolle, 1980) or Holtzman (Mitchell \& Yochim, 1970) strain rats kept in the same lighting regimen. We have therefore investigated the progesterone concentration changes and time of birth in rats kept in various lighting conditions using Sprague-Dawley or Wistar rats. The effects of pentobarbitone sodium or lesions of the suprachiasmatic nucleus (herein designated SCN), which has been proposed to be the oscillator of endogenous circadian rhythm (Moore \& Eichler, 1972; Inouye \& Kawamura, 1979; Rusak \& Groos, 1982), were also studied.

\section{Materials and Methods}

Animals. Primiparous Sprague-Dawley rats bred and reared in our laboratory and Wistar-derived rats purchased from the Animal Reproduction Company (Wistar-Imamichi strain; Chiba, Japan) were used. They were kept in a constant-temperature room $\left(23+1^{\circ} \mathrm{C}\right)$ under white fluorescent lighting with a light regimen of $14 \mathrm{~h}$ light and $10 \mathrm{~h}$ darkness (14L:10D; lights on at 05:00 h). They had free access to food and drinking water. At about 90 days of age, rats showing a regular 4-day cycle according to the vaginal smear cell patterns were caged with a male on the day of pro-oestrus. Successful mating was confirmed by the presence of spermatozoa in the vagina, and this day was designated as Day 1 of pregnancy. The period from Day 20 to birth was designated as the pre-partum period. The mated animals were isolated in individual cages until parturition.

Collection of samples. Blood samples were taken from individual rats at 4-h intervals from Day 20 or 21 by the tail-tip incision method (Takahashi et al., 1977), with the modification described by Murakami et al. (1986). Blood $(50 \mu \mathrm{l})$ was obtained by heparinized micropipette by aspiration by mouth. Each blood sample was duplicated in a volume of $20 \mu \mathrm{l}$ and mixed with $500 \mu \mathrm{l}$ distilled water before storage at $-20^{\circ} \mathrm{C}$ until progesterone analysis.

Determination of time of birth. The time of occurrence of parturition was determined by observation at 3-h intervals from 09:00 h on Day 21 until the birth. A dim red flash-light was used during the hours of darkness. The time of observation just after the delivery of the first young was designated as the time of birth, irrespective of litter size. However, females with $<4$ young were excluded, because a delay of parturition has been reported for rats producing small litters (Sherwood et al., 1985).

Experiment 1. Three different lighting conditions were used for pregnant Sprague-Dawley rats. In Group 1 (82 rats) the laboratory photoperiod (14L:10D; lights on at $05: 00 \mathrm{~h}$ ) was retained throughout pregnancy. For Group 2 (50 rats), the lighting regimen was kept at 14L:10D but lights were on from 17:00 to 07:00 $\mathrm{h}$ from Day 7 of pregnancy. The 48 rats in Group 3 were kept in constant darkness from Day 7 of pregnancy. A fourth group of 66 Wistar rats were maintained in 14L: 10D (lights on at 05:00 h) throughout pregnancy. In each group, 6-8 rats were supplied to take the serial blood samples, and the remaining rats were used only to determine the time of birth.

Experiment 2. Two groups of Sprague-Dawley rats were maintained under the reversed lighting condition described above from Day 7 of pregnancy. With Group I, on Day 20 of pregnancy the lights were switched on 8,5 or $2 \mathrm{~h}$ earlier or 5 or $8 \mathrm{~h}$ later. In each light regimen, blood was taken from 7 rats at 4-h intervals for $24 \mathrm{~h}$ starting at $11: 00 \mathrm{~h}$ on Day 21. With Group 2, 52 rats were injected intraperitoneally (i.p.) with pentobarbitone sodium (Nembutal: Abbott Laboratories, North Chicago, IL 60064, U.S.A., $31.5 \mathrm{mg} / \mathrm{kg}$ body wt) at 12:00, 15:00, 19:00, 21:00 or 23:00 h on Day 21 . As control, 20 rats were injected with saline $(9 \mathrm{~g} \mathrm{NaCl} / \mathrm{l})$ at the same times. At 15:00, 19:00 or $23: 00 \mathrm{~h}$ on Day 21, 24 rats were anaesthetized with ether. Blood samples were taken at 4-h intervals from 11:00 h on Day 21 to 15:00 $\mathrm{h}$ on Day 22. Then, the time of parturition was observed.

Experiment 3. Bilateral lesions of the SCN were made on Day 13 or 14 of pregnancy by an anodic direct current at stereotaxically determined co-ordinates obtained from a rat stereotaxic atias (Pellegrino \& Cushman, 1967). To avoid deposits of $\mathrm{Fe}^{2+}$ in the lesion area, the stainless-steel electrode with $1 \mathrm{~mm}$ platinum $(0.4 \mathrm{~mm}$ diameter) at the tip was insulated with epoxylite except for $0.2-0.3 \mathrm{~mm}$ at the tip. Rats were anaesthetized with i.p. pentobarbitone sodium and placed horizontally in a stereotaxis apparatus. The midline of the earbars served as a reference for the anteriorposterior positioning. The stereotaxic co-ordinates for the $\mathrm{SCN}$ electrode were set at $6.8 \mathrm{~mm}$ rostral, $\pm 0.35 \mathrm{~mm}$ lateral from the midline and $9.1 \mathrm{~mm}$ below from the top surface of the skull. In preliminary tests, when a direct current of $2 \mathrm{~mA}$ for $20 \mathrm{sec}$ was used, a large lesion including the SCN was observed, and many rats did not litter (dead young) until Day 25. In this study, therefore, to make a small lesion including the SCN, a direct current of $1.0 \mathrm{~mA}$ for $20 \mathrm{sec}$ was used. For sham-operations, the electrode was inserted into 7 rats but the current was not applied. To examine the elimination of circadian rhythm by the SCN lesion, patterns of drinking activity were determined at 4-h intervals for $24 \mathrm{~h}$ starting at 11:00 h on Day 19 by the method described previously (Sasaki et al., 1984). The operated rats were used to determine the time of parturition. Lesions were verified at the end of the experiment by microscopic examination of serial sections. 
Progesterone assay and statistical analysis. Progesterone was extracted from whole blood with petroleum ether, to remove corticosterone (mean recovery rate of progesterone extraction was $94 \%$ ). The extracts were subjected to radioimmunoassay (Murakami et al., 1979, 1982) using a specific antibody for progesterone. The steroids which showed any significant reactivity other than progesterone were corticosterone $(1.3 \%)$ and $17 \alpha$-hydroxyprogesterone $(7 \cdot 6 \%)$. The minimum detectable level was $15 \mathrm{pg} /$ tube. The intra-assay and inter-assay variances were $4 \cdot 2 \%(n=5)$ and $7.5 \%(n=6)$, respectively. The difference in the patterns of progesterone concentrations between two groups was analysed by analysis of variance. The distributions of time of birth were compared by $\chi^{2}$ analysis, or Student's $t$ test after angular transformation.

\section{Results}

\section{Experiment 1}

The distribution of time of birth of rats in different photoperiods is presented in Fig. 1. All distributions differed significantly from each other $(P<0.01)$. In Group 1, most births occurred at 09:00-15:00 h during the light period on Day 23 in Sprague-Dawley rats (Fig. 1a). Some gave birth

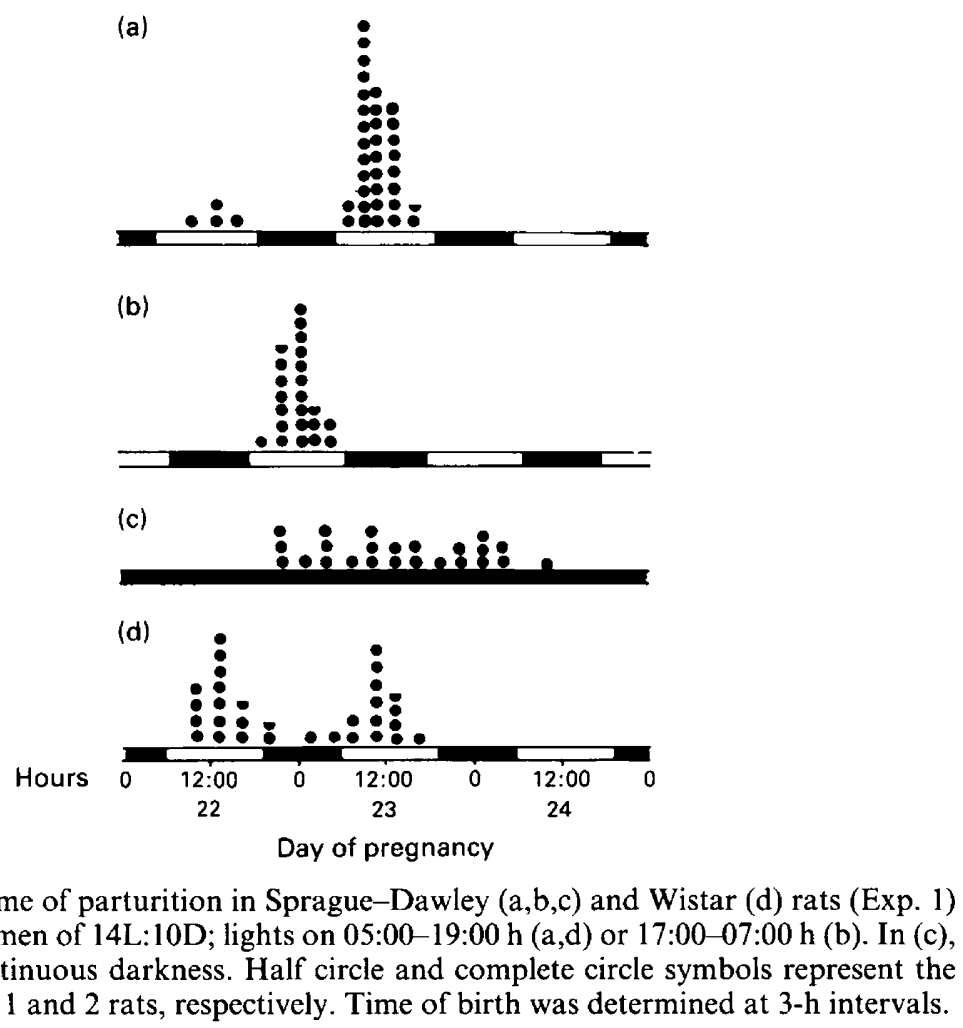

during the light phase on Day 22, but most did not produce litters during the dark period. In Group 2 rats, parturitions again occurred in the light period between 23:00 h on Day 22 and 05:00 h on Day 23 (Fig. 1b). In Group 3, births occurred at all times on Day 22, 23 and 24 (Fig. 1c). Many rats gave birth on Day 23. There were two main parturition times in Group 4 rats (Fig. 1d), one being the light period on Day 22, and the other the light period on Day 23; only 7 out of 52 rats gave birth during the dark period. Mean ( \pm s.e.m.) litter size was $13.6 \pm 2.3$ and $9.8 \pm 1.6$ in Wistar and Sprague-Dawley rats, respectively.

Peripheral blood progesterone concentrations in individual rats during the pre-partum period are shown in Fig. 2. Individual progesterone concentrations declined rapidly from about $40 \mathrm{ng} / \mathrm{ml}$ 

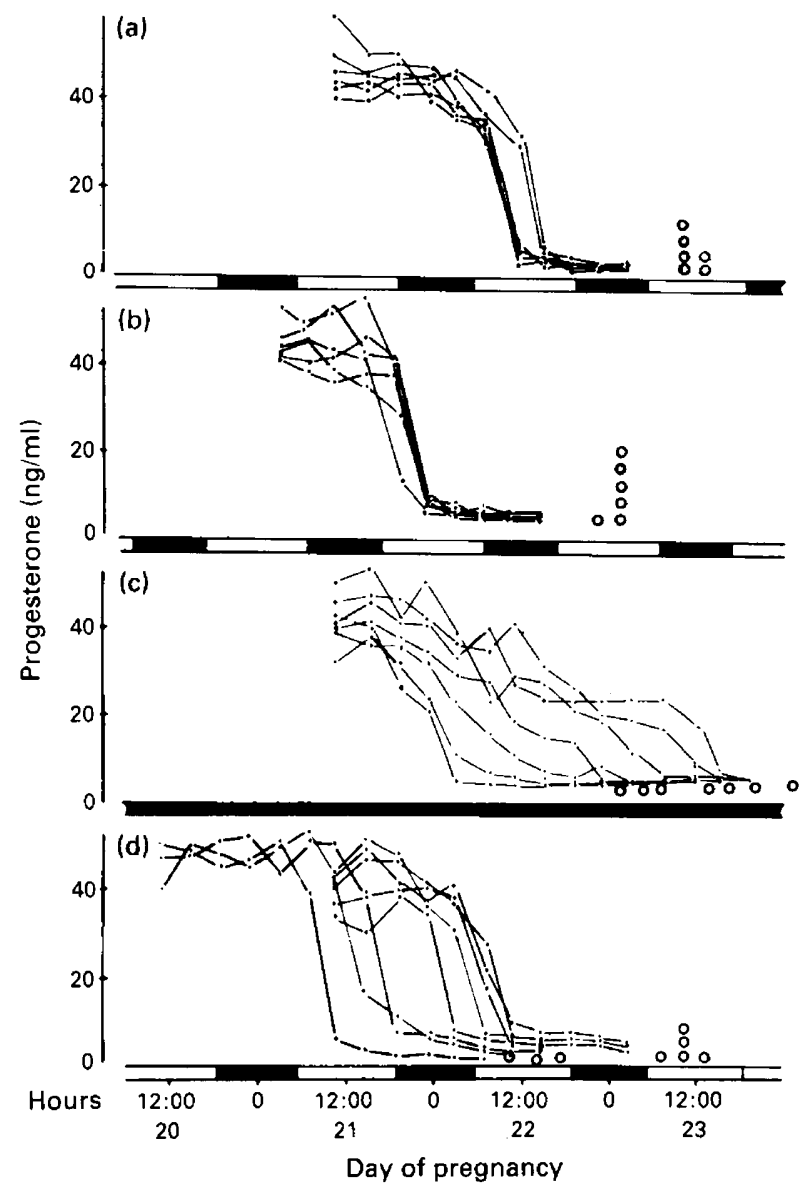

Fig. 2. The pre-partum decrease of blood progesterone concentrations in individual SpragueDawley $(a, b, c)$ and Wistar (d) rats in Exp. 1. Several blood samples were taken individually at 4-h intervals. Open circles represent the time of birth in rats from which samples were taken.

at $07: 00$ or 11:00 h to basal levels at 11:00 or 15:00 h during the light period on Day 22 in Group 1 (Fig. 2a). In Group 2, the decrease occurred between 19:00 and 23:00 h during the light period on Day 21 (Fig. 2b). No influence of the serial sampling on the time of birth was observed in Groups 1 and 2. However, progesterone decrease occurred independently of time of day in Group 3 rats (Fig. $2 \mathrm{c}$ ). The rate of decline progesterone values in Group 3 rats was more gradual than in Group 1 and 2. In Group 4, the progesterone decrease was observed independently of time of day between 11:00 h on Day 21 and 11:00 h on Day 22 (Fig. 2d).

\section{Experiment 2}

An advancement of the time of lights-on on Day 21 did not influence the time of progesterone decrease or the time of birth (Fig. 3a). However, when the time of lights-on was advanced by $8 \mathrm{~h}, \mathrm{a}$ significant difference was observed in the time of birth and progesterone profile of $(P<0.05)$, relative to those in other groups (Fig. 3a). When the time of lights-on was delayed for 5 or $8 \mathrm{~h}$, no significant differences were observed, relative to controls; in both the progesterone decrease occurred during the dark period (Fig. 3b). 


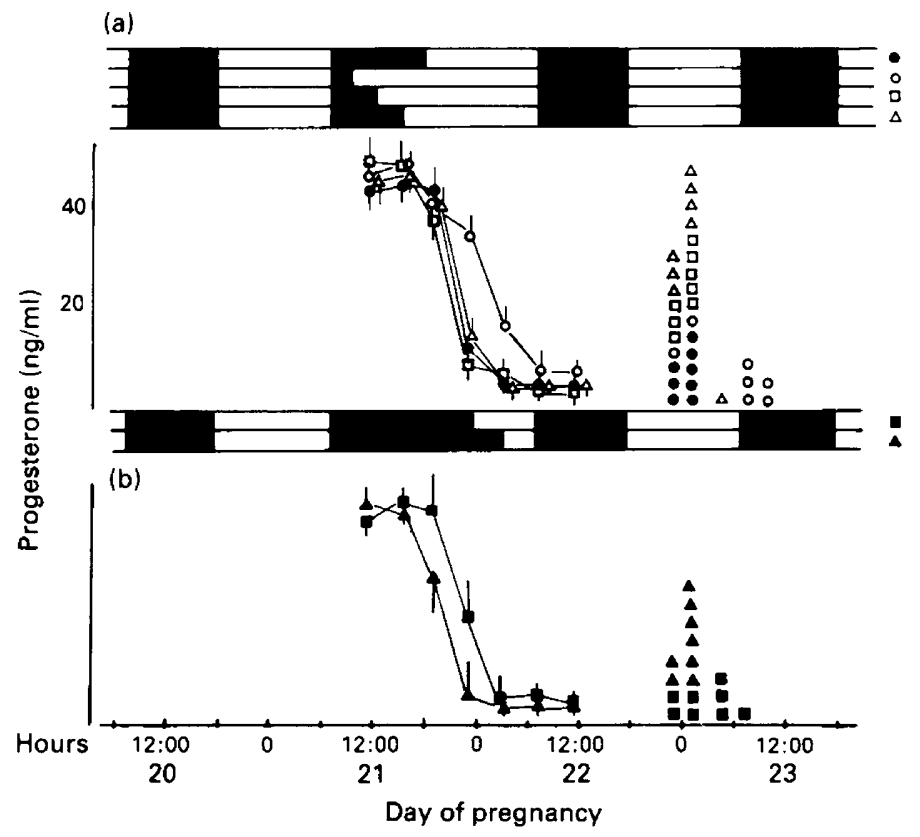

Fig. 3. Effect of change of photoperiod on Day 21 on pre-partum decrease of blood progesterone concentrations in Sprague-Dawley rats kept under reversed lighting conditions (Exp. 2). Time of lights-on was advanced for $8(\bigcirc), 5(\square)$ or $2 \mathrm{~h}(\triangle)$, or was delayed for $5(\boldsymbol{\square})$ or $8 \mathrm{~h}(\boldsymbol{\Delta})$ on Day 21 . The results are presented as mean \pm s.e.m. of $7-8$ rats. Time of birth is indicated by a symbol matching those for the progesterone values.

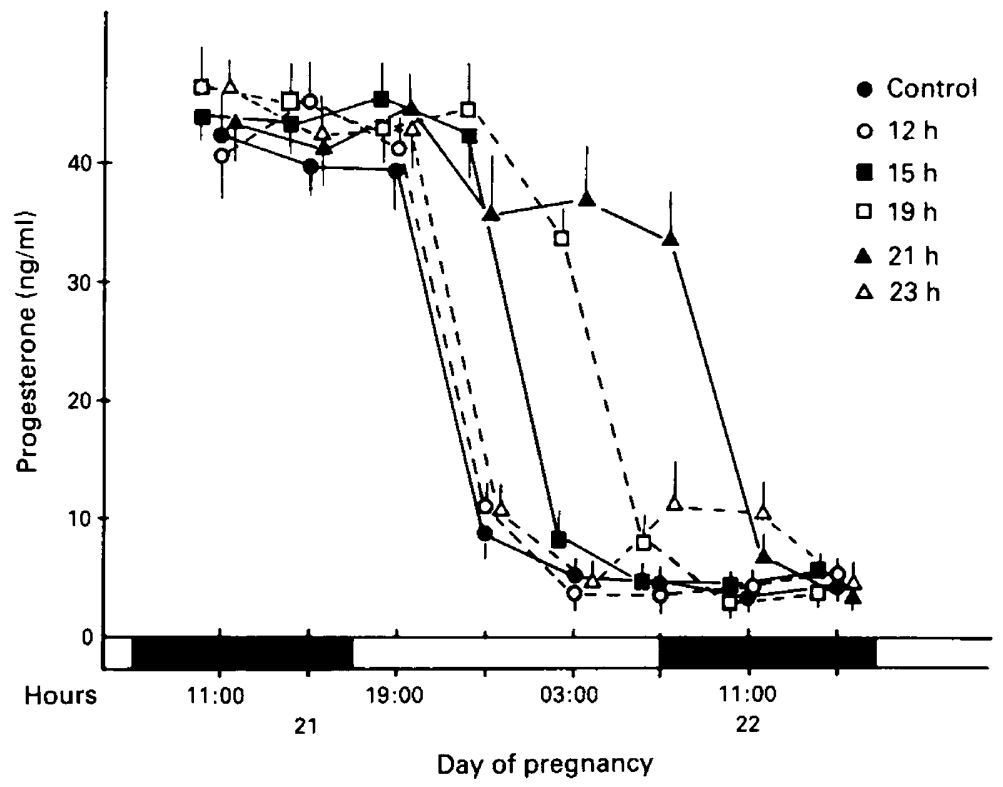

Fig. 4. Effect of treatment with pentobarbitone sodium on the pre-partum decrease of blood progesterone concentrations in Sprague-Dawley rats kept under a reversed lighting regimen (Exp. 2). Pentobarbitone sodium was injected i.p. at the times indicated in figure. Values are presented as mean \pm s.e.m. for $10-11$ rats. 
Table 1. Effect of injection of pentobarbitone sodium on the time of birth, determined at 3-h intervals, in Sprague-Dawley rats

\begin{tabular}{|c|c|c|c|c|c|c|c|c|c|}
\hline \multirow[b]{2}{*}{ Treatment } & \multirow{2}{*}{$\begin{array}{l}\text { Time of } \\
\text { treatment } \\
\text { (h) }\end{array}$} & \multirow{2}{*}{$\begin{array}{l}\text { No. of } \\
\text { rats }\end{array}$} & \multirow{2}{*}{$\frac{\text { Day } 22}{21: 00-24: 00 \mathrm{~h}}$} & \multicolumn{6}{|c|}{ Day 23} \\
\hline & & & & $03: 00 \mathrm{~h}$ & $06: 00 \mathrm{~h}$ & $09: 00 \mathrm{~h}$ & $12: 00 \mathrm{~h}$ & $15: 00 \mathrm{~h}$ & $19: 00 \mathrm{~h}$ \\
\hline Saline* & & 20 & 7 & 12 & 1 & - & - & - & - \\
\hline Ether & $\begin{array}{l}15: 00 \\
19: 00 \\
23: 00\end{array}$ & $\begin{array}{r}6 \\
10 \\
8\end{array}$ & $\begin{array}{l}2 \\
3 \\
4\end{array}$ & $\begin{array}{l}3 \\
6 \\
4\end{array}$ & $\begin{array}{l}1 \\
1\end{array}$ & - & - & - & - \\
\hline $\begin{array}{l}\text { Pento- } \\
\text { barbitone } \\
\text { sodium }\end{array}$ & $\begin{array}{l}12: 00 \\
15: 00 \\
19: 00 \\
21: 00 \\
23: 00\end{array}$ & $\begin{array}{l}10 \\
10 \\
11 \\
11 \\
10\end{array}$ & $\begin{array}{l}2 \\
0 \\
0 \\
0 \\
2\end{array}$ & $\begin{array}{l}8 \\
2 \\
1 \\
0 \\
3\end{array}$ & $\begin{array}{l}\overline{2} \\
2 \\
2 \\
2\end{array}$ & $\begin{array}{l}\overline{2} \\
4 \\
3 \\
3\end{array}$ & $\begin{array}{l}3 \\
4 \\
4 \\
\end{array}$ & $\frac{1}{2}$ & $\frac{-}{-}$ \\
\hline
\end{tabular}

*Injected to each of 4 rats at 12:00, 15:00,19:00,21:00 and 23:00 h, and pooled data are presented.

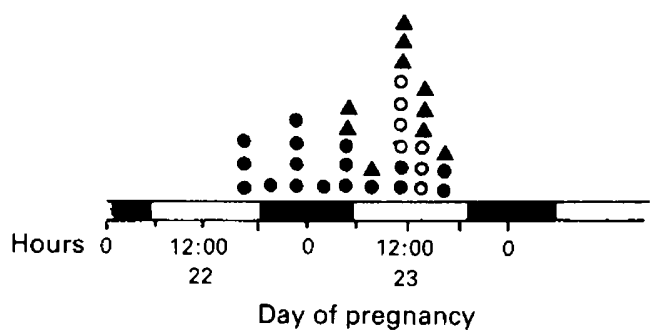

Fig. 5. Time of parturition in rats with a complete SCN lesion ( $)$, a partial SCN lesion $(\boldsymbol{\Delta})$ or an intact SCN $(O)$.

In the rats treated with pentobarbitone sodium, complete recovery, judged by inspection, was observed $3-4.5 \mathrm{~h}$ after anaesthesia. The litter size was normal in rats anaesthetized with pentobarbitone $(9 \cdot 4 \pm 2 \cdot 2)$ or ether $(9 \cdot 6 \pm 2 \cdot 7)$. The treatment with pentobarbitone at 15:00, 19:00 or $21: 00 \mathrm{~h}$, but not 12:00 or 23:00 h, on Day 21 resulted in delay of the time of the progesterone decrease (Fig. 4) and in the time of birth, except for the group injected at 12:00 h (Table 1). The ether anaesthesia did not cause any significant effect on the time of parturition (Table 1).

\section{Experiment 3}

The 24-h pattern of water intake showed no rhythmicity in rats with complete SCN lesions, compared with that in control rats and those with partial SCN lesions. Histological examination indicated that 55\% rats had complete $\mathrm{SCN}$ lesions, 35\% partial lesions and $10 \%$ were unsuccessfully lesioned. Complete lesion of the $\mathrm{SCN}$ resulted in elimination of light-dependent parturition (Fig. 5b). Rats gave birth independently of time of day between Day 21 and 23. However, a strong tendency to advancement of the time of birth was observed, relative to that in control rats. Many rats with partial or unsuccessful lesions gave birth at the usual time (Fig. 5).

\section{Discussion}

Most births occurred between 09:00 and 15:00 h during the light period on Day 23 in SpragueDawley rats maintained under the usual light-dark regimen. When the photoperiod was reversed 
on Day 7, parturition occurred between $23: 00$ and $05: 00 \mathrm{~h}$ on Day 22-23. These results may indicate that parturition generally occurs during the light period. Lilit \& Yeager (1974) demonstrated that time of blastocyst implantation was influenced by the photoperiod. In this study, however, the time of parturition may not be associated with the time of implantation, since the reversed photoperiod was given after the expected day of implantation (Day 5 of pregnancy). Lincoln \& Porter (1976) and Sherwood et al. (1983) reported that advancement of photoperiod near mid-pregnancy advanced the time of birth. These results, including our observation, suggest that the time of parturition is closely associated with photoperiod.

Lincoln \& Porter (1979) demonstrated that rat exposed to continuous darkness on only Day 23 gave birth during the same period as did controls. In this study, no extensive influence was observed on the time of birth even when the time of lights-on was changed on Day 21. Furthermore, the rats exposed to continuous darkness for a long time gave birth independently of time of day between Days 22 and 24 . These results suggest that light-dependent parturition may be associated with an endogenous circadian system, and that light may be a strong entrainer of the time of parturition, but not the main trigger.

There is evidence that light is mediated by retinohypothalamic projection to the SCN (Moore \& Eichler, 1972) which has been proposed to be an oscillator of endogenous circadian system (Moore, 1973; Inouye \& Kawamura, 1979; Rusak \& Groos, 1982). Complete lesion of this site scattered the time of parturition, suggesting that the SCN may be involved in determination of the time of birth. Lincoln \& Porter (1979) reported that the lesion of the hypothalamus including the SCN caused two notable changes in the timing of birth, some $29 \%$ of animals failing to give birth and the remaining giving birth independently of time of day. Although the reason for failure of birth by lesion of the SCN is not clear, large lesions of the hypothalamus may be the cause (Honma et al., 1984). Parturition in the rat is brought about by intricate mechanisms (Fuchs, 1973; Thorburn \& Challis, 1979) involving adrenal function (Bosc \& Nicolle, 1979, 1980), pituitary hormones (Fuchs et al., 1974; Gordon \& Sherwood, 1985), relaxin (Downing \& Sherwood, 1985), prostaglandins (Dukes et al., 1974; Labhsetwar \& Watson, 1974; Strauss et al., 1975; Buckle \& Nathanielsz, 1975), ovarian steroids (Catala \& Deis, 1973; Thorburn \& Challis, 1979), or relationship between fetus and mother (Sherwood et al., 1985). The mechanism affected by lesion of the $\mathrm{SCN}$ is uncertain. For example, lesion of the SCN eliminates the circadian rhythm of adrenocortical steroid (Moore \& Eichler, 1972) which is considered to be one of the triggers of parturition (Thorburn \& Challis, 1979).

The pre-partum decrease of blood progesterone in Sprague-Dawley rats occurred rapidly between 07:00 and 15:00 $\mathrm{h}$ during the light period in the usual lighting condition. When the photoperiod was reversed on Day 7 , the progesterone decrease also occurred in the light period, between 19:00 and 23:00 h on Day 21. These results are consistent with a view that the progesterone decrease is correlated with daily photoperiod, as Sherwood et al. (1983) have demonstrated. However, it is not clear whether the light-dependent progesterone decrease is associated with an endogenous circadian system. This study provides two pieces of evidence: (1) the decrease occurred independently of time of day in rats exposed to continuous darkness for a long time (Fig. 2c), and (2) change of the lighting regimen on Day 21 only had very little effect on the progesterone decrease on Day 21 (Fig. 3). These results suggest that the progesterone decrease may also be closely associated with an endogenous circadian system. The reason why the time of progesterone decrease was delayed by advancement of lights-on for $8 \mathrm{~h}$ is not known. However, one possibility is that a phase shift may be present: time-dependent phase shifts by a light pulse have been reported for free-running rats (Daan \& Pittendrigh, 1976).

In Wistar rats, the distribution of parturition was biphasic, as observed previously (Bosc \& Nicolle, 1980), and suggests that parturition in Wistar rats is also associated with photoperiod. However, the progesterone decrease occurred independently of time of day. Although the reason for this difference between Wistar and Sprague-Dawley rats is not clear, the sensitivity to or dependence of the probable luteolytic factor with photoperiod may be different. 
In Sprague-Dawley rats, the fact that the progesterone decrease occurred during a limited period of the day suggests that rapid luteolysis may also occur during a limited period. The progesterone decrease was delayed by treatment with pentobarbitone sodium at 15:00, 19:00 or 21:00 h, but not at 12:00 or 23:00 h, on Day 21, suggesting that the nervous system may be associated with the decrease between 15:00 and 23:00 h on Day 21. The nature of the putative luteolytic process associating with circadian rhythm (Thorburn \& Challis, 1979) and processes involved with a possible direct effect on the ovary of pentobarbitone are unknown.

This work was supported by Ministry of Education, Science and Culture of Japan (60760237).

\section{References}

Bartholomeusz, R.K., Bruce, N.W., Martin, C.E. \& Hartmann, P.E. (1976) Serial measurement of arterial plasma progesterone levels throughout gestation and parturition in individual rats. Acta endocr., Copenh. 82, 436442.

Bosc, M.J. \& Nicolle, A. (1979) Effect of a stress on the course of labor or on the time of parturition in normal or adrenalectomized rat. Annls Biol. anim. Biochim. Biophys. 19, 31-44.

Bose, M.J. \& Nicolle, A. (1980) Influence of photoperiod on the time of parturition in the rat. I. Effect of the length of daily illumination on normal or adrenalectomized animals. Reprod. Nutr. Develop. 20, $735-745$.

Buckle, J.W. \& Nathanielsz, P.W. (1975) A comparison of the characteristics of parturition induced by prostaglandin $\mathrm{F}_{2 \alpha}$ infused intraaortically with those following ovariectomy in the rat. J. Endocr. 64, 257-266.

Catala, S. \& Deis, R.P. (1973) Effect of oestrogen upon parturition, maternal behaviour and lactation in ovariectomized pregnant rats. J. Endocr. 56, 219-225.

Daan, S. \& Pittendrigh, C.S. (1976) A functional analysis of circadian pacemaker in nocturnal rodents. II. The variability of phase response curve. J. comp. Physiol. 106, 253-266.

Downing, S.J. \& Sherwood, O.D. (1985) The physiological role of relaxin in the pregnant rat. $I$. The influence of relaxin on parturition. Endocrinology 116, 1200-1205.

Dukes, M., Chester, R. \& Atkinson, P. (1974) Effect of oestradiol and prostagrandin $F_{2 n}$ on the timing of parturition in the rat. J. Reprod. Fert. 38, 325-334.

Fuchs, A.R. (1973) Parturition in rabbits and rats. Mem. Soc. Endocr. 20, 163-185.

Fuchs, A.R., Mok, E. \& Sundaram, K. (1974) Luteolytic effects of prostaglandins in rat pregnancy and reversal of LH. Acta endocr., Copenh. 76, 583-596.

Gordon, W.L. \& Sherwood, O.D. (1982) Evidence that luteinizing hormone from the maternal pituitary gland may promote antepartum release of relaxin, luteolysis, and birth in rats. Endocrinology 111, 1299-1310.

Honma, S., Honma, K., Shirakawa, T. \& Hiroshige, T. (1984) Maternal phase setting of fetal circadian oscillation underlying the plasma corticosterone rhythm in rats. Endocrinology 114, 1791-1796.

Inouye, S.T. \& Kawamura, H. (1979) Persistence of circadian rhythmicity in a mammalian hypothalamic 'island' containing the suprachiasmatic nucleus. Proc. natn. Acad. Sci. U.S.A. 79, 5962-5966.

Labhsetwar, A.P. \& Watson, D.J. (1974) Temporal relationship between secretory pattern of gonadotropins, estrogen, progestin and prostaglandin $F_{2 a}$ in periparturient rats. Biol. Reprod. 10, 103-110.

Lilit, N. \& Yeager, V.L. (1974) Effect of photoperiod on time of blastocyst implantation in the rat. Proc. Soc. exp. Biol. Med. 145, 894-896.

Lincoln, D.W. \& Doyle, J.C. (1978) Does the prepartum rise in the plasma level of prolactin determine the time of delivery in rats? IRCS Med. Sci. 6, 436.

Lincoln, D.W. \& Porter, D.G. (1976) Timing of the photoperiod and the hour of birth in rats. Nature, Lond. 260, 780-781.

Lincoln, D.W. \& Porter, D.G. (1979) Photoperiodic dissection of endocrine events at parturition. Anim. Reprod. Sci. 2, 97-115.

Mitchell, J.A. \& Yochim, J.M. (1970) Influence of environmental lighting on duration of pregnancy in the rat. Endocrinology 87, 472-480.

Moore, R.Y. (1973) Retinohypothalamic projection in mammals: a comparative study. Brain Res. 49, 403-409

Moore, R.Y. \& Eichler, V.B. (1972) Loss of circadian adrenal corticosterone rhythm following suprachiasmatic lesions in the rat. Brain Res. 42, 201-206.

Murakami, N., Takahashi, M. \& Suzuki, Y. (1979) Indispensable role of peripheral progesterone levels for the occurrence of prolactin surges in pseudopregnant rat. Biol. Reprod. 21, 263-268.

Murakami, N., Takahashi, M., Suzuki, Y. \& Honma, K. (1982) Responsiveness of dispersed rat luteal cells to luteinizing hormone and prolactin during estrous cycle and early pseudopregnancy. Endocrinology 111, 500-508.

Murakami, N., Takahashi, K., Kuroda, H. \& Etoh, T. (1986) Restricted feeding regimen affects the diurnal prolactin surge but not nocturnal surge in pseudopregnant rat. Jap. J. vet. Sci. 48, 29-34

Pellegrino, L.J. \& Cushman, A.J. (1967) A Stereotaxic Atlas of the Rat Brain. Appleton Century Crofts, New York.

Plaut, S.M., Grota, L.J., Ader, R. \& Graham, C.W. (1970) Effect of handling and the light dark cycle on time of parturition in the rat. Lab. Anim. Care. 20, 447-453. 
Rusak, B. \& Groos, G. (1982) Suprachiasmatic stimulation phase shifts rodent circadian rhythm. Science, N.Y. 215, 1407-1409.

Sanyal, M.K. (1978) Secretion of progesterone during gestation in the rat. J. Endocr. 79, 179-190.

Sasaki, Y., Murakami, N. \& Takahashi, K. (1984) Critical period for the entrainment of the circadian rhythm in blinded pups by dams. Physiol. Behav. 33, 105-109.

Sherwood, O.D., Downing, S.J., Golos, T.G., Gordon, W.L. \& Tarbell, M.K. (1983) Influence of light-dark cycle on antepartum serum relaxin and progesterone immunoreactivity levels and on birth in the rat. Endocrinology 113, 997-1003.

Sherwood, O.D., Downing, S.J., Rieber, A.J., Fraley, S.W., Bohrer, B.C. \& Richardson, B.C. (1985) Influence of litter size on antepartum serum relaxin and progesterone immunoreactivity levels and on birth in the rat. Endocrinology 116, 2554-2562.
Strauss, J.F., Sokoloski, J., Caploe, P., Duffy, P., Mintz, G. \& Stambaugh, R.L. (1975) On the role of prostaglandins in parturition in the rat. Endocrinology 96, 1040-1045.

Takahashi, K., Inoue, K. \& Takahashi, Y. (1977) Parallel shift in circadian rhythm of adrenocortical activity and food intake in blind and intact rats exposed to constant illumination. Endocrinology 100, 1097-1 107.

Thorburn, G.D. \& Challis, J.R.G. (1979) Endocrine control of parturition. Physiol. Rev. 59, 863-916.

Received 26 February 1986 